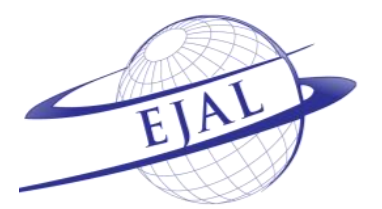

\title{
Pre-service Language Teachers' Use of Social Networking Sites for Language Learning: A Quantitative Investigation
}

\author{
Osman Solmaz a * \\ a Dicle University, Department of Foreign Language Education, Diyarbakır, 21280, Turkey \\ Received 31 January 2019 | Received in revised form 20 May 2019 | Accepted 01 July 2019
}

\begin{abstract}
APA Citation:
Solmaz, O. (2019). Pre-service language teachers' use of social networking sites for language learning: A quantitative investigation. Eurasian Journal of Applied Linguistics, 5(3), 423-439. Doi: 10.32601/ejal.651394
\end{abstract}

\begin{abstract}
This study examined pre-service language teachers' attitudes towards social networking site (SNS) use for language learning, their SNS practices for improving their target languages, and the relationship between them. 279 English and German language teacher candidates participated in the surveys designed for the present study. The statistical analyses of the data revealed that pre-service language teachers had positive perceptions towards SNS use for the purpose of language development and they took advantage of SNSs to improve their target languages. It was also found that variables such as participants' departments, years of study, and self-reported SNS literacies significantly affected their attitudes towards SNS use and their SNS practices. Finally, the quantitative data obtained confirmed a significant correlation between teacher candidates' attitudes and their SNS practices for language learning in general and for particular skills. The results are discussed within the context of relevant scholarship, and the study is concluded with recommendations for future research.
\end{abstract}

(C) 2019 EJAL \& the Authors. Published by Eurasian Journal of Applied Linguistics (EJAL). This is an open-access article distributed under the terms and conditions of the Creative Commons Attribution license (CC BY-NC-ND) (http://creativecommons.org/licenses/by-nc-nd/4.0/).

Keywords: social networking sites; pre-service teachers; language learning; attitudes; digital literacies

\section{Introduction}

The advent of new forms of computer-mediated-communication (CMC) brought academic attention to the integration of such spaces into pedagogical contexts. These technologies are often characterized by features supporting user-generated content such as digital texts, audios, videos, and images. Affording their users to interact with others and form groups based on shared interests through the use of multimodal resources, social networking sites (SNSs) are among the technologies such as collaborative writing platforms (Ayan \& Seferoğlu, 2017) and open access video materials (Lesnov, 2017), which have been approached with educational purposes in mind. The ubiquity and mobility of such socio-interactive technologies prompted research exploring the adoption of SNSs in second language learning and teaching

\footnotetext{
* Corresponding author. Tel.: +90-412-248-8001/8832

E-mail address: osolmaz@dicle.edu.tr
} 
contexts (Lomicka \& Lord, 2016; Reinhardt, 2019; Solmaz, 2018). The growing body of research highlighted that SNSs promoted the improvement of skills including writing (Dizon, 2016) and listening (Fouz-González, 2017) as well as the development of sociopragmatic awareness (Blattner \& Lomicka, 2012; Reinhardt \& Ryu, 2013) and intercultural competence (Özdemir, 2017). Previous research also revealed that SNSs provided an authentic space where learners found opportunities to negotiate meaning through interaction with native speakers (Liu, 2017; Solmaz, 2017), socialize into communities formed by themselves or/and target language users (Hattem, 2014; Lomicka \& Lord, 2012), and engage in construction and maintenance of dynamic identity representations (Chen, 2013; Klimanova \& Dembovskaya, 2013).

Language learners' perceptions and reactions towards the incorporation of SNSs into language learning contexts were found to be positive in general including the particular strand of research that focused on pre-service teachers (e.g., Carpenter, 2015; Kearney \& Maher, 2019). Examining teacher candidates' educational use of social media and their experiences of being involved in pedagogical practices featuring SNSs, previous research showed that pre-service teachers used social media for professional development and had positive attitudes towards the adoption of these mediums in educational settings (Carpenter, Tur, \& Marín, 2016; Krutka, Nowell, \& Whitlock, 2017). Research particularly addressing pre-service English language teachers' attitudes of using social media for pedagogical purposes in Turkish higher education context illustrated that teacher candidates had favorable opinions for the implementation of such technologies in language learning and teaching contexts (e.g., Bağcı \& Atar, 2018; Balçıkanlı, 2015). However, the relationship between language teacher candidates' attitudes towards SNS use for language learning and their SNS practices for the improvement of their target languages have yet to be explored. Further research also needs to comparatively address the attitudinal differences between pre-service language teachers enrolled in different departments. To fill the void, the current study attempted to examine both English and German language teacher candidates' perceptions towards SNS use for language improvement, their SNS use for developing their target languages, and the correlation between them.

\section{Literature Review}

The following literature offers a cumulative understanding of the previous research by encompassing studies on pre-service teachers' social media use in global contexts and pre-service language teachers' use of social media in Turkish higher education context.

\subsection{Pre-service Teachers' Social Media Use in Global Contexts}

Social media use of pre-service teachers has been investigated through several perspectives in the literature, which include teacher candidates' educational and professional use of social media, their pedagogical intentions to adopt these tools, and their experiences of pedagogical practices involving social media. These studies either 
approached social media in general or with a focus on a particular site such as Facebook or Twitter. Mostly being quantitative in nature, the previous scholarship covered a wide array of pedagogical contexts including those in Australia, Nigeria, and the United States. It is documented that pre-service teachers adopt social networking sites (SNSs) for various reasons such as research, maintaining communication, collaboration, entertainment, socialization, and sharing knowledge (Akgün, 2016; Şendurur, Şendurur, \& Yılmaz, 2015), and they have a more comprehensive knowledge of these spaces and use them more compared to other Web 2.0 tools, with YouTube and Moodle being exceptions (García-Martín \& GarcíaSánchez, 2017).

A major strand of research examined educational and academic use of SNSs by preservice teachers in multiple geographical contexts. To begin with, Danner and Oufani (2018) examined 104 pre-service English language teachers' perceptions of SNS use for academic purposes and found that teacher candidates had positive attitudes. Furthermore, no significant differences based on variables such as gender, year of study, and habits of SNS use were found. Similarly, Acarlı and Sağlam (2015) developed a survey within the framework of Technology Acceptance Model (TAM) and administered it on 322 teacher candidates in Turkey. The results concluded that preservice teachers were willing to use social media professionally upon graduation. On the other hand, the recent qualitative study by Kearney and Maher (2019) showed that pre-service teachers had already been utilizing mobile technologies including SNSs for supporting their professional learning networks (PLNs). The study, which examined 11 teacher candidates' mobile learning practices, highlighted a nuanced picture of how mobile technology use of pre-service teachers mediated their practices for professional development. Finally, Şendurur et al. (2015) conducted a research on the relationship between Turkish pre-service teachers' attitudes towards SNS use and their academic achievements. The data gathered from 412 participants revealed that teacher candidates were aware of potential positive and negative effects of SNS use on their academic success although no direct relationship between attitude and academic achievement were detected.

Researchers delved into issues beyond attitudinal work, which demonstrated learners' perceptions following a pedagogical implementation featuring a social networking medium. To illustrate, Carpenter (2015) incorporated Twitter into a required course for undergraduate teacher education students and engaged 20 preservice teachers in a series of activities on Twitter. As a result, he observed that Twitter created an arena for his students whose conversations were extended beyond spatio-temporal limitations. Although participants were active during the semester, the majority of them discontinued professional SNS activity in the following semester. In a similar yet transnational study, Carpenter et al. (2016) guided 153 pre-service teachers in the U.S. and Spain to use Twitter as part of coursework and examined their perceptions towards the medium. Teacher candidates from both contexts had positive experiences and intentions to adopt it for their professional learning. However, they were relatively negative about using the medium with their future 
students. In another study conducted at three different universities in the U.S. context, Krutka et al. (2017) engaged 71 teacher candidates in both asynchronous and synchronous discussions on Twitter in addition to other social media practices and assignments. Data collected from surveys and written reflections revealed shortcomings such as mismatch in instructors' expectations and participants' use, students' limited vision or intention of social media use for teaching in the future, and positive aspects including academic contributions, formation of a small community, and most importantly increased participation and an encouraged voice. Finally, Luo, Sickel, and Cheng (2017) similarly involved 46 pre-service teachers in a series of synchronous Twitter chats through a series of educational hashtags such as \#edchat as part of a hybrid format course. The analysis of participants' tweets, and their preand post-activity reflections yielded that live discussions provided a space for them to engage with education professionals across the globe. Although students' overall experiences were found to be positive in general, it was underscored that several factors (e.g., participants' prior experience, perceived benefits and challenges, and their perceptions towards the medium) impact their attitudes towards synchronous chats on Twitter.

\subsection{Pre-service English Language Teachers' Social Media Use in Turkey}

There is a growing body of research investigating Turkish pre-service language teachers' attitudes of using social media for pedagogical purposes. Predominantly concentrated on English language teacher candidates, the studies often revealed that students had positive perceptions towards educational use of social media. In her quantitative research, Başöz (2016) explored the role of social media in 120 preservice EFL teachers' language learning experiences. She found that students had positive attitudes, and they viewed social media as a regular component of their language learning experiences, which positively contributed to their development of vocabulary, reading, and listening skills. Analyzing the effect of several variables, she found that participants' years of study significantly affected their attitudes. In their recent study, Bağcı and Atar (2018) examined 140 pre-service EFL teachers' acceptance and use of social networks for teaching and found a high level of acceptance and use. They also found that teacher candidates with previous social network experience for learning had a significantly higher rate of acceptance and use, which indicated that these students might be more likely to use social networks for pedagogical purposes when they become teachers. In a similar study but specifically focusing on Facebook, Çakır and Atmaca (2015) explored 221 pre-service EFL teachers' views regarding the implementation of Facebook in English language classroom. Additionally, they conducted oral interviews with 21 teacher candidates, which provided a more comprehensive picture. Findings revealed that a high majority of participants had favorable perceptions towards integrating Facebook into English class. The results also showed that many students believed that teaching English by using Facebook was more suitable for intermediate and advanced learners rather than beginner-level students. 
In addition to these quantitative studies illuminating a needed perspective, several studies shed light on language teachers' views of particular SNSs following a pedagogical teaching experience. In his mixed-methods study, Balçıkanlı (2015) integrated Facebook into a college-level course and aimed to examine to the extent such an experience could have impact on pre-service EFL teachers' pedagogical use of Facebook. The statistical analysis of the data gathered from 113 participants yielded a significantly positive relationship between the adoption of Facebook and its use for educational purposes. It was also found that participants' purposes of Facebook use were positively associated with their use of Facebook for pedagogical aims. Furthermore, teacher candidates reported favorable feelings towards the integration of Facebook into learning contexts due to its potential to create an interesting experience for learners. In another study, Okumuş and Yurdakal (2016) aimed to understand pre-service EFL teachers' opinions on the use of Facebook for providing feedback to their peers as part of microteaching experience. The project, which involved 38 English language teacher candidates, required participants to upload their microteaching videos to a private Facebook group and comment on their colleagues' performances. The analysis of the open-ended questionnaire data showed that participants found the technique helpful for developing their teaching and linguistic skills including writing, speaking, and reading. The findings also displayed that watching microteaching videos of their peers enabled teacher candidates to become familiar with new teaching methods and techniques. Finally, Solmaz (2016) implemented Twitter in a university-level course taken by 36 pre-service EFL teachers. Following a series of sessions which required active participation of teacher candidates on Twitter, quantitative and qualitative data revealed that participants reported positive experiences as well as a perceived increase in their social network literacies. The results further illustrated that domains like Twitter could be employed as arenas to create and maintain a community of inquiry in higher education context.

\subsection{The present study}

There has been a variety of research on pre-service language teachers' attitudes towards the use of social media as well as studies on their social media use for professional and educational purposes. However, the previous research appears to have a lack of focus on teacher candidates' perceptions towards social networking site (SNS) use and its effect on their SNS use for developing various language skills and areas. Additionally, attitudes and SNS use of language teacher candidates enrolled in different departments have yet to be comparatively addressed as well. In an effort to fill the void in the literature in both local and global contexts, the current study combined several factors to examine both English and German pre-service language teachers' attitudes towards SNS use for language learning, their SNS use for improving their target languages, and the correlation between them. Although many studies interchangeably use the terms of social networking sites and social media, it is important to note that the present study adopts social networking sites (SNSs) (e.g., Facebook, Twitter, Instagram) rather than social media, which "is the set 
encompassing various types of applications" (Zourou, 2012, p. 3) including technologies such as social bookmarking, virtual worlds, online games and social networking sites (Conole \& Alevizou, 2010).

Considering the aforementioned issues and the gap in the literature, the following research questions were addressed in the current study:

1. What are the attitudes of pre-service English and German language teachers as learners towards the use of social networking sites (SNSs) for foreign language learning?

1.1. Do pre-service language teachers' attitudes towards SNS use for language learning differ in accordance with the variables of gender, age, department, year of study, frequency of SNS use, and SNS literacies?

2. What is the level of pre-service English and German language teachers' social networking site (SNS) use for foreign language learning?

2.1. To what extent do they use SNS for improving their reading, writing, listening, speaking, vocabulary, and grammar?

2.2. Does their SNS use for language learning differ in accordance with the variables of gender, age, department, year of study, frequency of SNS use, and SNS literacies?

3. What are the correlations between pre-service teachers' attitudes towards SNS use for language learning and their SNS practices for improving target language?

\section{Method}

\subsection{Participants}

Participants were 279 pre-service language teachers pursuing an undergraduate degree in English and German Language Teaching at a state university in southeastern Turkey. The group consisted of 215 female (77.1\%) and 64 male (22.9\%) teacher candidates. The mean age of the participants was 22.32 in the range of 18 and 34. Of the participants, 163 pre-service teachers (58.4\%) were studying at the department of English Language Teaching (ELT) and $116(41.6 \%)$ of them were enrolled in German Language Teaching (GLT) program. 67 (24\%) were first-year, 68 $(24.4 \%)$ were second-year, $80(28.7 \%)$ were third-year, and $64(22.9 \%)$ of the participants were in their fourth year.

Participants' background information regarding their social networking site (SNS) usage, frequency, and literacies were collected as well. When participants were asked about which SNSs they used, they often had two or more selections. Instagram was the most popular SNS and it was used by 205 (36.5\%) participants, which was followed by Facebook $(\mathrm{N}=113,20.1 \%)$, Twitter $(\mathrm{N}=82,14.6 \%)$, SnapChat $(\mathrm{N}=56,10 \%)$. 105 (18.7\%) participants indicated that they used other SNSs such as WhatsApp. 173 (62\%) pre-service teachers selected Instagram as the most frequently used SNS, while the weekly frequency of SNS use was distributed across different time periods. 88 
(31.5\%) participants used SNSs less than 5 hours, 73 (26.2\%) of them spent 5-9 hours, 47 (16.8\%) learners indicated 10-14 hours, 37 (13.3\%) participants spent 15-19 hours, and finally $34(12.2 \%)$ pre-service teachers used more than 20 hours for SNSs in a week. Participants' self-reported SNS literacies were mixed although the majority selected "Good" ( $\mathrm{N}=116,41.6 \%)$, and "Very Good" ( $\mathrm{N}=63,22.6 \%)$. The remaining participants reported that they had "Average" (N=87, 31.2\%), "Bad" (N=9, 3.2\%), or "Very Bad" (N=4, 1.4\%) SNS literacies.

\subsection{Instruments}

The data collection instruments consisted of a background questionnaire and two surveys measuring learners' attitudes towards SNS use for language learning and their SNS use for language development. The background questionnaire elicited sociodemographic information including age, gender, department, years of study, SNS memberships, the most frequently used SNS, weekly SNS use, and SNS literacies. Each of the 5-scale Likert-type surveys was consisted of 18 items and designed by the author. The development of the survey was accomplished in 3 stages: 1) A pool of recurring themes and items used in the previous research was created as a result of a comprehensive literature scan. 2) A total of 48 items were analyzed and categorized into two groups: Attitudes towards SNS use for Language Learning and SNS Practices for Language Learning. Following the initial analysis, three experts in the field evaluated for its face and content validity. Necessary changes and edits were made based on their feedback. 3) Later, a pilot test was administered to 40 language teacher candidates through two surveys consisting of 42 items. Further changes were made following the feedback from teacher candidates regarding vagueness of certain items and similarities between some of them. The final version of the surveys consisted of 36 items. The first survey consisted of items aimed to examine participants' attitudes towards using SNSs for language learning and they were assessed on a scale ranging from one to five (1=completely disagree, $2=$ disagree, $3=$ neither agree nor disagree, $4=$ agree, $5=$ completely agree). The second survey was composed of 18 items which included 3 items for each of the following language skills and areas: reading, writing, speaking, listening, vocabulary, grammar. The items were evaluated on a scale ranging from one to five similar to the first scale.

\subsection{Procedures}

Following the formal permissions from the Institutional Review Board at university, the purpose, significance, and methodology of the study were clarified to the participants. They were also informed that their participation was voluntary and they could discontinue participation at any time. All of the participants knew that confidentiality and anonymity of the collected data would be protected. The distribution and collection of the data was completed in about three weeks in the spring semester of the 2017-2018 academic year. 
The data obtained from the surveys were analyzed using the Statistical Package for Social Sciences (SPSS). The version of SPSS 25.0 for Windows was adopted to compute mean scores, frequency rates, standard deviations, and statistical percentages for variables including age, gender, department, year of study, the frequency of SNS use, and SNS literacies. The Cronbach's Alpha coefficient of the first scale was found to be .90 , while the second scale achieved an alpha coefficient of .89, both of which reflected a high level of reliability. While the percentage of variance was $65.98 \%$ for the first scale, the rate was $70.34 \%$ for the latter, which indicated a high level of validity for the goals of the study. Then, independent-samples t-test and oneway ANOVA were conducted to investigate the differences between items in the scales and the independent variables such as gender, age, department, and SNS literacies. Levene's Test for equality of variances was also employed to test the assumption of homogeneity of variance while running the $t$-test procedures. The results are reported accordingly when the homogeneity of variance assumption has been violated. It is important to underscore here that due to a major imbalance across reported SNS literacies (e.g., $M=4$ for very bad, and $M=9$ for bad), SNS literacies were combined into two groups throughout the study: 1) average or below, 2) good or very good. Finally, Pearson product-moment correlation coefficient test was computed to investigate the relationships between participants' attitudes towards SNS use and their own SNS practices for linguistic development.

\section{Results}

\subsection{Attitudes of language learners towards SNS use for language learning}

The first research question aimed to understand language learners' attitudes towards using social networking sites (SNSs) for improving their target language. English and German language learners mostly agreed with the survey items $(M=$ $3.90, S D=.66$ ), as presented in Table 1 . In other words, basic descriptive statistics revealed that participants had positive attitudes towards SNS use for developing target languages, with minimum mean scores above $3.00(S D=1.22)$ and the highest mean score being $4.42(S D=.99)$.

Table 1. Descriptive statistics of language learners' attitudes towards SNS use for language learning

\begin{tabular}{|c|c|c|}
\hline$N=279$ & $M$ & $S D$ \\
\hline 1. I follow some people / accounts in my target language on social networking sites (SNSs). & 3.51 & 1.51 \\
\hline 2. I find materials related to my target language on SNSs. & 3.62 & 1.15 \\
\hline 3. I believe that SNSs are not helpful for developing language(s).* & 4.42 & .99 \\
\hline 4. For me, SNSs are important aspects of improving the target language. & 3.70 & 1.19 \\
\hline 6. I think that SNSs offer a stress-free environment for improving target language. & 3.79 & 1.16 \\
\hline 7. SNSs enable learners to reach samples of various language uses in real life contexts. & 4.05 & .98 \\
\hline 8. SNSs assist learners in their autonomous language learning practices. & 4.00 & .99 \\
\hline 9. Using SNSs while learning language increases my motivation. & 3.85 & 1.17 \\
\hline
\end{tabular}


11. I can continue my language learning process at anytime and anywhere thanks to SNSs.

12. I can gain experiences that are suitable for my learning style through SNSs.

13. I have doubts for improving language through SNS use.*

15. I think that improving language through SNSs is more enjoyable compared to traditional methods. $3.92 \quad 1.14$

16. I can access native speakers of my target language thanks to SNSs.

17. I can access various dialects and accents of my target language through SNSs. 4.20

18. I think that SNSs are useful tools for improving language in general.

* The item is reversely coded.

Participants' attitudes towards SNS use were examined in relation to the following variables: gender, age, and the frequency of SNS use. Statistical $t$-test analyses revealed no significant differences between male $(M=3.78, S D=.71)$ and female $(M=$ $3.95, S D=.65)$ participants' attitudes towards SNS use for language learning $[t(277)$ $=1.78, p=.076, d=0.25]$. Furthermore, One-Way ANOVA tests were run to obtain the results of other variables and the tests yielded statistically nonsignificant results for age $\left[F(17,261)=.128, p>.05, \eta_{\mathrm{p} 2}=0.08\right]$, and frequency of SNS use $[F(4,274)=$ $\left..771, p>.05, \mathrm{\eta}_{\mathrm{p} 2}=0.007\right]$. The $t$-test analyses were conducted for the variables of department and SNS literacies and significant results were revealed (Table 2). It is possible to say that pre-service teachers of English and participants with above average self-reported SNS literacies have more positive attitudes towards SNS use for language development.

Table 2. Results of $t$-tests for the role of department and SNS literacies on attitudes towards SNS use

\begin{tabular}{|c|c|c|c|c|c|c|c|c|}
\hline & $N=279$ & $N$ & $M$ & $S D$ & $t$ & $d f$ & $p$ & $d$ \\
\hline \multirow[t]{2}{*}{ Department } & English & 163 & 4.03 & .63 & \multirow{2}{*}{3.722} & \multirow{2}{*}{277} & \multirow{2}{*}{$.000^{*}$} & \multirow{2}{*}{0.46} \\
\hline & German & 116 & 3.73 & .67 & & & & \\
\hline \multirow[t]{2}{*}{ SNS Literacies } & Average or below & 100 & 3.75 & .68 & \multirow{2}{*}{2.927} & \multirow{2}{*}{277} & \multirow{2}{*}{$.004 *$} & \multirow{2}{*}{0.37} \\
\hline & Good or very good & 179 & 3.99 & .63 & & & & \\
\hline
\end{tabular}

$* p<.05$ level.

Finally, One-Way ANOVA was conducted to see the effect of participants' year of study on their attitudes towards SNS use for language learning (Table 3). The analysis yielded that year of study was a significant factor $[F(3,275)=.017, p<.05$, $\left.\eta_{\mathrm{p} 2}=0.04\right]$. In an effort to find out the year of studies in which significant differences were observed, a post hoc Tukey test was conducted. The results suggested that the attitudes of fourth year pre-service teachers' attitudinal behaviors towards SNS use for language development were significantly more positive than those of the first year teacher candidates. 


\begin{tabular}{llccccc}
\hline Source of Variance & Sum of Squares & $d f$ & Mean square & $F$ & $p$ & Difference \\
\hline Between groups & 4.438 & 3 & 1.479 & & & \\
Within groups & 118.356 & 275 & .430 & 3.437 & $.017^{*}$ & D $>$ A \\
Total & 122.794 & 278 & & & & \\
\hline
\end{tabular}

${ }^{*} p<.05$ level. (A: 1st year, B: 2nd year, C: 3rd year, D: 4th year)

\subsection{SNS use of language learners for foreign language learning}

The second question addressed language learners' SNS uses for improving their target language. The 18-item survey was categorized in six parts, each of which had 3 items corresponding to SNS use for reading, listening, speaking, writing, vocabulary, and grammar. Descriptive analysis of the data showed that both English and German language learners agreed with the survey items $(M=3.66, S D=.74)$ (Table 4). The analysis further revealed that participants mostly made use of SNSs for improving their listening $(M=3.91, S D=.94)$, which was closely followed by vocabulary $(M=$ $3.85, S D=.92)$, reading $(M=3.80, S D=.89)$, and speaking $(M=3.76, S D=.94)$. Grammar $(M=3.47, S D=.90)$ and writing $(M=3.19, S D=.96)$ were the language areas/skills they sought to develop least. In this case, it is possible to say that learners engaged in SNS practices, through which they developed their receptive skills (i.e., listening, reading) more than productive skills (i.e., speaking, writing).

Table 4. Descriptive statistics of language learners' SNS practices for language learning

\begin{tabular}{|c|c|c|c|}
\hline Skill/Area & Statements & $M$ & $S D$ \\
\hline \multirow[t]{4}{*}{ Listening } & & 3.91 & .94 \\
\hline & 1. I listen to music in my target language on SNSs. & 3.87 & 1.24 \\
\hline & 7. I make use of SNSs to develop my listening skill. & 3.80 & 1.25 \\
\hline & 13. I watch videos on SNSs in my target language. & 4.07 & 1.10 \\
\hline \multirow[t]{4}{*}{ Reading } & & 3.80 & .89 \\
\hline & 2. I benefit from reading materials in my target language on SNSs. & 3.56 & 1.19 \\
\hline & 8. I read texts which I see in my target language on SNSs. & 4.19 & 1.03 \\
\hline & 14. I take advantage of SNSs to develop my reading skill in target language. & 3.64 & 1.15 \\
\hline \multirow[t]{4}{*}{ Speaking } & & 3.76 & .94 \\
\hline & 3. I think that my speaking skill improves when I use target language on SNSs. & 3.73 & 1.17 \\
\hline & 9. SNSs assist me in becoming a better target language speaker. & 3.68 & 1.12 \\
\hline & 15. I make use of SNSs to improve my pronunciation in target language. & 3.87 & 1.19 \\
\hline \multirow[t]{4}{*}{ Writing } & & 3.19 & .96 \\
\hline & 4. I exchange written correspondence with others in target language on SNSs. & 2.99 & 1.42 \\
\hline & 10. I utilize SNSs to develop my writing skill in target language. & 3.13 & 1.24 \\
\hline & 16. I use my target language in the posts I share on SNSs. & 3.44 & 1.34 \\
\hline \multirow[t]{4}{*}{ Vocabulary } & & 3.85 & .92 \\
\hline & 5. I strengthen my vocabulary in target language by seeing or using them on SNSs. & 3.49 & 1.23 \\
\hline & 11. I take advantage of SNSs to improve my vocabulary knowledge in target language. & 3.94 & 1.13 \\
\hline & 17. I use SNSs to search for the meaning of some words that I do not know. & 4.10 & 1.22 \\
\hline \multirow[t]{2}{*}{ Grammar } & & 3.47 & .90 \\
\hline & 6. SNSs allow me to see and repeat rules and structures through authentic examples. & 3.56 & 1.20 \\
\hline
\end{tabular}


Participants' SNS use for improving their target language was examined through $t$ test for the variables of gender, department, and SNS literacies, and One-Way ANOVA for the variables of age, year of study, and frequency of SNS use. The statistical analysis yielded no significant results for gender $[t(277)=0.66, p=.511, d$ $=0.08]$, age $\left[F(17,261)=.568, p>.05, \eta_{\mathrm{p} 2}=0.06\right]$, year of study $[F(3,275)=.253, p$ $\left.>.05, \mathrm{\eta}_{\mathrm{p} 2}=0.015\right]$, and frequency of SNS use $\left[F(4,274)=.240, p>.05, \mathrm{\eta}_{\mathrm{p} 2}=0.02\right]$. However, there were statistically significant differences in terms of their departments and self-reported SNS literacies (Table 5). The results displayed that English language teacher candidates and participants with above-average self-reported SNS literacies engaged in more SNS practices for the purpose of improving their target language.

Table 5. Results of $t$-tests for the role of multiple variables on SNS use for language learning

\begin{tabular}{|c|c|c|c|c|c|c|c|c|}
\hline & $N=279$ & $N$ & $M$ & $S D$ & $t$ & $d f$ & $p$ & $d$ \\
\hline \multirow[t]{2}{*}{ Department } & English & 163 & 3.80 & .70 & \multirow{2}{*}{3.671} & \multirow{2}{*}{277} & \multirow{2}{*}{$.000^{*}$} & \multirow{2}{*}{0.45} \\
\hline & German & 116 & 3.47 & .76 & & & & \\
\hline \multirow[t]{2}{*}{ SNS Literacies } & Average or below & 100 & 3.48 & .77 & \multirow{2}{*}{3.002} & \multirow{2}{*}{277} & \multirow{2}{*}{$.003^{*}$} & \multirow{2}{*}{0.38} \\
\hline & Good or very good & 179 & 3.76 & .71 & & & & \\
\hline
\end{tabular}

$* p<.05$ level.

A series of $t$-test analyses were conducted to detect the effect of SNS literacies on participants' SNS use for developing various language skills and areas. The results showed no significant differences for using SNSs in developing speaking $[t(277)=$ $-1.69, p=.092, d=0.21]$ and grammar $[t(277)=-1.62, p=1.05, d=0.20]$. Levene's test for equality of variances was found to be violated for reading $(p=.015<.05)$ and vocabulary $(p=.016<.05)$. Due to these violations, $t$ statistics not assuming homogeneity of variance were computed. The results revealed no significant differences in SNS use for developing reading $[t(277)=-1.92, p=.056, d=0.24]$, and vocabulary $[t(277)=-1.87, p=.063, d=0.23]$. However, there was a meaningful difference for improving listening and writing skills (Table 6). It is possible to say that higher SNS literacies make more positive impact on developing listening and writing skills compared to other areas.

Table 6. Results of $t$-tests for the role of SNS literacies on SNS use for developing specific language skills

\begin{tabular}{|c|c|c|c|c|c|c|c|c|}
\hline & $N=279$ & $N$ & $M$ & $S D$ & $t$ & $d f$ & $p$ & $d$ \\
\hline Listening & Good or very good & 179 & 4.08 & .89 & 3.132 & 277 & $.002^{*}$ & 0.42 \\
\hline \multirow[t]{2}{*}{ Writing } & Average or below & 100 & 2.89 & .96 & \multirow{2}{*}{3.912} & \multirow{2}{*}{277} & \multirow{2}{*}{$.000 *$} & \multirow{2}{*}{0.49} \\
\hline & Good or very good & 179 & 3.35 & .92 & & & & \\
\hline
\end{tabular}

${ }^{*} p<.05$ level. 


\subsection{Correlations between learners'attitudes and SNS practices for language learning}

Pearson product-moment correlation coefficient test was performed to quantify the relationships among language learners' attitudes and SNS practices for language development in general and for particular language skills. A significant correlation between variables was found in different magnitudes (Table 8). Overall, the results indicated a high positive correlation $(r=.72, p<.01)$ between learners' attitudes and SNS use for improving target language in accordance with the second language research specific benchmarks ( $r=.25$ small; $r=.40$ medium; $r=.60$ large) (Plonsky \& Oswald, 2014). Furthermore, there were strongly positive correlations between language learners' attitudes and SNS use for improving vocabulary $(r=.64)$, listening $(\mathrm{r}=.61)$, speaking $(\mathrm{r}=.61)$, and moderately positive correlations between attitudes and developing grammar $(\mathrm{r}=.54)$, reading $(\mathrm{r}=.53)$, and writing $(\mathrm{r}=.52)$. No weak or negative correlations were found across the variables included in the test.

Table 8. Correlations between learners' attitudes and SNS practices for language learning

\begin{tabular}{|c|c|c|c|c|c|c|c|c|}
\hline Variables & 1 & 2 & 3 & 4 & 5 & 6 & 7 & 8 \\
\hline 1. SNS Attitudes & - & & & & & & & \\
\hline 2. SNS Use (All skills) & $.72^{* *}$ & - & & & & & & \\
\hline 3. Reading & $.53^{* *}$ & $.81^{* *}$ & - & & & & & \\
\hline 4. Listening & $.61^{* *}$ & $.83^{* *}$ & $.72^{* *}$ & - & & & & \\
\hline 5. Speaking & $.61^{* *}$ & $.81^{* *}$ & $.60^{* *}$ & $.62^{* *}$ & - & & & \\
\hline 6. Writing & $.52^{* *}$ & $.75^{* *}$ & $.53^{* *}$ & $.52^{* *}$ & $.48^{* *}$ & - & & \\
\hline 7. Vocabulary & $.64^{* *}$ & $.84^{* *}$ & $.58^{* *}$ & $.64^{* *}$ & $.65^{* *}$ & $.54^{* *}$ & - & \\
\hline 8. Grammar & $.54^{* *}$ & $.75^{* *}$ & $.47^{* * *}$ & $.51^{* * *}$ & $.54^{* *}$ & $.50^{* * *}$ & $.63^{* *}$ & - \\
\hline
\end{tabular}

$* * p<.01$ level. $\mathrm{N}=279$.

\section{Discussion and Conclusions}

The main purpose of the present study was to investigate pre-service English and German teachers' attitudes towards social networking site (SNS) use for language learning, their SNS practices for improving various language skills, and the correlation between their attitudes and practices.

The results of the statistical analyses revealed that both English and German language teacher candidates had positive perceptions towards the use of SNSs for developing target languages. The study confirms the findings of previous studies (e.g., Çakır \& Atmaca, 2015; Danner \& Oufani, 2018) in which majority of pre-service language teachers were in favor of educational use of SNSs including purposes such as language learning and teaching. It is important for teacher candidates to have positive perceptions towards such technologies since they might approach them as potential educational materials/settings and leverage them in their teaching when they graduate. However, it is necessary for teacher educators to structure meaningful activities which will enable teacher candidates to successfully transfer them to future experiences (Krutka et al., 2017). Furthermore, the role of social media in teaching 
and learning a foreign language should be addressed theoretically and practically through courses offered in ELT programs in higher education contexts, which directly centered on the implementation of technology into L2 teaching and learning processes. Experiences of teacher candidates involving the application of theory into practice could develop them as "theoretical practitioners who not only encounter, but also refine accepted ideas about language teaching and learning" before becoming teachers (Dimitroff \& Dimitroff, 2018, p. 147).

The examination of variables such as gender, age, and frequency of SNS use was found to have no significant effect on attitudinal behaviors of pre-service language teachers. These findings are in tune with Çakır and Atmaca (2015) and Danner and Oufani (2018) regarding gender, and Başöz (2016) and Danner and Oufani (2018) regarding frequency of SNS use, and Bağcl and Atar (2018) regarding all three variables. On the other hand, there were significant differences in terms of variables including participants' department, year of study, and self-reported SNS literacies. These results suggested that the attitudes of pre-service teachers of English, participants with above-average SNS literacies, and fourth year teacher candidates were more positive compared to German language teacher candidates, participants with average or below SNS literacies, and first year students, respectively. It might be speculated that senior students, who previously engaged in microteaching activities and regularly teach as part of their practicum, may observe and acknowledge the value of social media as a pedagogical medium more compared to relatively inexperienced first year teacher candidates who are typically more focused on developing their target language rather than teaching it. Regarding departmental differences, there may be several factors including but not limited to the ubiquity of English across social media platforms, motivation and language levels of teacher candidates, and their educational backgrounds. Compared to previous works, the findings regarding students' year of study are similar to the study of Başöz (2016), who found significant differences among her participants according to their grades, but in contradiction with the work of Danner and Oufani (2018), which revealed no significant differences between 3rd and 4th year teacher candidates. In terms of SNS literacies, it can be argued that the findings are in line with the previous research (e.g., Bağcı \& Atar, 2018; Çakır \& Atmaca, 2015), which showed that students' having SNS accounts and prior experiences with the mediums have statistically higher rate of potential SNS use for educational purposes. As a practical implication for language teacher educators and teacher candidates, it is suggested that teacher candidates engage in activities which will positively contribute to the development of their digital literacies, including their skillful navigation across multiple modalities in social media. It is recommended that professional development courses addressing the needs of teacher educators to adopt materials curated from social media and pedagogically implement them in higher education context. It is hoped that teacher candidates will develop a positive perspective towards the integration of social media as part of language teaching and learning as a result of being exposed to such materials as early as in their first year of study. Finally, it is worthwhile noting that the results 
pertaining to significant differences between English and German language teacher candidates warrant further investigation as there is a lack of relevant research in the field.

The study further showed that both English and German pre-service teachers agreed that they took advantage of SNS for developing their target languages. The analysis yielded that participants mostly improved their listening, vocabulary, reading, and speaking while grammar and writing were the areas/skills they sought to develop least. These findings concur well with the findings of Başöz (2016) except the improvement of writing skills. Pre-service EFL teachers in the previous work believed that social media could assist them in developing their writing skills unlike participants in the present study. This difference may be attributed to the different amount of target language use in written form across SNS platforms, which might have affected participants' perceptions towards developing writing although further examination is needed. Aside from these findings, it was revealed that there were no significant differences regarding variables such as gender, age, year of study, and frequency of SNS, which are in good agreement with the previous work (e.g., Başöz, 2016). In addition, department and SNS literacies were found to have significant effect on participants' SNS practices for language development. It is to say that English language teacher candidates and participants with above-average SNS literacies utilized SNS for developing their target language compared to German preservice teachers and participants with average or below SNS literacies, respectively. Previous findings displayed the relationship between prior experience with SNSs and their educational use (e.g., Çakır \& Atmaca, 2015), but this study contributes through the finding which exhibits an added importance of participants' SNS literacies in their perceptions towards SNS use for pedagogical purposes. The finding regarding the departmental differences in SNS practices for language learning is also valuable although the underlying factors such as individual differences, levels of motivation, and previous SNS experiences have yet to be addressed in detail. Given the differences across teacher candidates in English and German departments, it is recommended that teacher educators in certain departments might need to emphasize the potential of social media as a language learning and development tool more frequently and present more specific opportunities for maximizing the benefits of digital technologies for educational purposes.

The data also revealed that higher SNS literacies had more positive impact on the development of listening and writing skills compared to other areas. The result widens our knowledge on the role of SNS literacies on the development of particular skills by using SNSs and it also necessitates a thorough examination of the relationship between SNS literacies and the improvement of specific language skills. Nevertheless, the finding is in accordance with the research examining SNS use from a more general educational perspective. For example, Carpenter et al. (2016) reported that U.S. pre-service teachers perceived more value in using Twitter for professional development compared to their Spanish counterparts. The differences between participants' hashtag literacies resulting in variations of their access to a multitude of 
resources and educators was considered as a possible explanation. In a similar vein, it might be claimed that participants with higher SNS literacies can make more use of SNSs for language learning and teaching. However, this particular finding regarding SNS literacies should be interpreted with caution since it is based on self-reported data provided by participants. Considering social media technologies started to be employed for developing specific language skills (Balbay \& Kilis, 2017) and online tasks increase language learners' motivations (Lamri \& Hamzaoui, 2018), it is important that language teaching programs in higher education context provide preservice teachers opportunities to equip themselves with appropriate knowledge to locate, adopt, and successfully use technologies assisting them in improving certain language skills.

Finally, the statistical data indicated a significant correlation between teacher candidates' attitudes towards SNS use for improving target language and their SNS practices for language learning in general and for particular skills and areas. As reported by Balçıkanlı (2015), the evidence found points to the relationship between students' feelings and perceptions towards SNS and their adoption of the medium for educational purposes. This finding stresses the critical role of possessing positive attitudes in engaging in SNS practices for language learning purposes. Teacher education programs' guidance and emphasis on teaching with technological tools including social media might enable teacher candidates to develop positive attitudes towards them, which might translate into using them for improving themselves. Such individual experiences are likely to increase their awareness, which might result in pre-service teachers providing assistance and guidance to their students in the future.

A number of limitations associated with the present study need to be considered. Firstly, the study is based on self-reported data from pre-service language teachers. To illustrate, the data included teacher candidates' perceptions of their SNS literacies rather than their actual level of SNS literacies. Therefore, limitations inherent to this type of descriptive data are applicable. In this regard, it is recommended that future research employs a scale prepared to measure computer/SNS literacies of participants when designing and conducting a similar study. Secondly, although the study featured a representative sample of English and German language pre-service teachers, the data should be interpreted with caution when generalizing the results since it did not include teacher candidates of other languages like French. In this respect, future research may replicate this study with larger samples featuring preservice teachers enrolled in various departments across the country. Furthermore, an international study including participants from different countries might provide valuable results, which might confirm or refute the findings of the present study. Finally, although the quantitative nature of the study illuminates a broader perspective, it could have been strengthened with qualitative data featuring interviews with teacher candidates. In the light of this limitation, future research may include qualitative data collection instruments in an effort to provide a more nuanced picture of the relationship between language learners' attitudes and their SNS practices for language learning. 


\section{References}

Acarlı, D. S., \& Sağlam, Y. (2015). Investigation of pre-service teachers' intentions to use of social media in teaching activities within the framework of technology acceptance model. Procedia - Social and Behavioral Sciences, 176, 709-713.

Akgün, İ. H. (2016). Investigation of social studies teachers' intended uses of social networks in terms of various variables. Educational Research and Reviews, 11(2), 67-77.

Ayan, E., \& Seferoğlu, S. S. (2017). Using EtherPad for online collaborative writing activities and learners with different language learning strategies. Eurasian Journal of Applied Linguistics, 3(2), 205-233.

Bağc1, H., \& Atar, C. (2018). Pre-service English teachers' acceptance and use of social networks for teaching purposes. Journal of Theoretical Educational Science, UBEK-2018, 189-203.

Balbay, S., \& Kilis, S. (2017). Students' Perceptions of the use of a YouTube channel specifically designed for an Academic Speaking Skills Course. Eurasian Journal of Applied Linguistics, 3(2), 235-251.

Balçıkanlı, C. (2015). Prospective English language teachers' experiences in Facebook: Adoption, use and educational use in Turkish context. International Journal of Education and Development using Information and Communication Technology, 11(3), 82-99.

Başöz, T. (2016). Pre-service EFL teachers' attitudes towards language learning through social media. Procedia - Social and Behavioral Sciences, 232, 430-438.

Blattner, G., \& Lomicka, L. (2012). Facebook-ing and the social generation: A new era of language learning. ALSIC 15(1). Retrieved from http://alsic.revues.org/24313.

Carpenter, J. P. (2015). Pre-service teachers' micro-blogging: Professional development via Twitter. Contemporary Issues in Technology and Teacher Education, 15(2), 209-234.

Carpenter, J., Tur, G., \& Marín, V. I. (2016). What do U.S. and Spanish pre-service teachers think about educational and professional use of Twitter? A comparative study. Teaching and Teacher Education, 60, 131-143.

Chen, H. (2013). Identity practices of multilingual writers in social networking spaces. Language Learning \& Technology, 17(2), 143-170.

Conole, G., \& Alevizou, G. (2010). Literature Review: The Use of Web 2.0 in Higher Education: A report commissioned by the Higher Education Academy. Milton Keynes: The Open University.

Çakır, A., \& Atmaca, Ç. (2015). Pre-service teacher perceptions about the use of Facebook in English language teaching. Digital Culture \& Education, 7(2), 110-130.

Danner, R. B., \& Oufani, F. N. (2018). Pre-service English language teachers' use of social network sites: implication for higher education. UNESWA Journal of Education, 1(1), 73 87.

Dimitroff, A., \& Dimitroff, A. (2018). New Beginnings: Trials and triumphs of newly hired teachers. Eurasian Journal of Applied Linguistics, 4(2), 135-153.

Dizon, G. (2016). A comparative study of Facebook vs. paper-and-pencil writing to improve L2 writing skills. Computer Assisted Language Learning, 29(8), 1249-1258.

Fouz-González, J. (2017). Pronunciation instruction through Twitter: the case of commonly mispronounced words. Computer Assisted Language Learning, 30(7), 631-663.

García-Martín, J., \& García-Sánchez, J. (2017). Pre-service teachers' perceptions of the competence dimensions of digital literacy and of psychological and educational measures. Computers \& Education, 107, 54-67.

Hattem, D. (2014). Microblogging activities: Language play and tool transformation. Language Learning \& Technology, 18(2), 151-174. 
Kearney, M., \& Maher, D. (2019). Mobile learning in pre-service teacher education: Examining the use of professional learning networks. Australasian Journal of Educational Technology, 35(1), 135-148.

Klimanova, L., \& Dembovskaya, S. (2013). L2 Identity, Discourse, and Social Networking in Russian. Language Learning \& Technology, 17(1), 69-88.

Krutka, D. G., Nowell, S., \& Whitlock, A. M. (2017). Towards a Social Media Pedagogy: Successes and Shortcomings in Educative Uses of Twitter with Teacher Candidates. Journal of Technology and Teacher Education, 25(2), 215-240.

Lamri, C. E., \& Hamzaoui, H. (2018). Developing ELP students' reading skills through a blended approach. Eurasian Journal of Applied Linguistics, 4(2), 389-407.

Lesnov, R. O. (2017). Using videos in ESL listening achievement tests: Effects on difficulty. Eurasian Journal of Applied Linguistics, 3(1), 67-91.

Liu, S. H. (2017). Text-based negotiated interaction of NNS-NNS and NNS-NS dyads on Facebook. ReCALL, 29(3), 294-312.

Lomicka, L., \& Lord, G. (2012). A tale of tweets: Analyzing microblogging among language learners. System, 40, 48-63.

Lomicka, L., \& Lord, G. (2016). Social Networking and Language Learning. In F. Fiona and L. Murray (Eds.), The Routledge Handbook of Language Learning and Technology (pp. 255268). London; New York, NY: Routledge.

Luo, T., Sickel, J., \& Cheng, L. (2017). Preservice Teachers' Participation and Perceptions of Twitter Live Chats as Personal Learning Networks. TechTrends, 61, 226-235.

Okumuş, K., \& Yurdakal, İ.H. (2016). Peer feedback through SNSs (Social Networking Sites): Pre-Service teachers' views about using Facebook for peer feedback on microteachings. Elementary Education Online, 15(4), 1206-1216.

Özdemir, E. (2017). Promoting EFL Learners' intercultural communication effectiveness: A focus on Facebook. Computer Assisted Language Learning, 30(6), 510-528.

Plonsky, L., \& Oswald, F. L. (2014). How big is big? Interpreting effect sizes in L2 research. Language Learning, 64, 878-912.

Reinhardt, J. (2019). Social media in second and foreign language teaching and learning: Blogs, wikis, and social networking. Language Teaching, 52(1), 1-39.

Reinhardt, J., \& Ryu, J. (2013). Using social network-mediated bridging activities to develop socio-pragmatic awareness in elementary Korean. International Journal of ComputerAssisted Language Learning and Teaching, 3(3), 18-33.

Solmaz, O. (2016). \#Beyond140: Helping pre-service teachers construct a community of inquiry on Twitter. TOJET: The Turkish Online Journal of Educational Technology, 15(4), 1-15.

Solmaz, O. (2017). Autonomous language learning on Twitter: Performing affiliation with target language users through \#hashtags. Journal of Language and Linguistic Studies, 13(2), 204-220.

Solmaz, O. (2018). A critical review of research on social networking sites in language teaching and learning. Contemporary Educational Technology, 9(3), 315-330.

Şendurur, P., Şendurur E., \& Yılmaz, R. (2015). Examination of the social network sites usage patterns of pre-service teachers. Computers in Human Behavior, 51, 188-194.

Zourou, K. (2012). On the attractiveness of social media for language learning: A look the state of the art. $A L S I C, 15(1)$. Retrieved from http://alsic.revues.org/2436.

\section{Copyrights}

Copyright for this article is retained by the author(s), with first publication rights granted to the Journal.

This is an open-access article distributed under the terms and conditions of the Creative Commons Attribution license (CC BY-NC-ND) (http://creativecommons.org/licenses/by-nc-nd/4.0/). 